\title{
Nutrition knowledge, attitudes, behaviours and the influencing factors among non-parent caregivers of rural left-behind children under 7 years old in China
}

\author{
Cai Tan ${ }^{1}$, Jiayou Luo ${ }^{1, *}$, Rong Zong ${ }^{2, *}$, Chuhui Fu' ${ }^{1}$, Lingli Zhang ${ }^{1}$, Jinsong Mou ${ }^{1}$ and \\ Danhui Duan ${ }^{1}$ \\ 'Department of Women and Children Health, School of Public Health, Central South University, Xiangya Road \\ 110, Changsha 410078, People's Republic of China: ${ }^{2}$ Xiangya Hospital, Central South University, Changsha \\ 410078, People's Republic of China
}

Submitted 13 January 2009: Accepted 29 December 2009: First published online 3 March 2010

\begin{abstract}
Objective: To explore and compare nutrition knowledge, attitudes and behaviours (KAB) between non-parent and parent caregivers of children under 7 years old in Chinese rural areas, and to identify the factors influencing their nutrition KAB.

Design: Face-to-face interviews were carried out with 1691 non-parent caregivers and 1670 parent caregivers in the selected study areas; multivariate logistic regression models were used to identify the factors influencing nutrition KAB in caregivers.

Results: The awareness rate of nutrition knowledge, the rate of positive attitudes and the rate of optimal behaviours in non-parent caregivers $(52 \cdot 2 \%, 56 \cdot 9 \%$ and $37 \cdot 7 \%$, respectively) were significantly lower than in the parent group $(63 \cdot 8 \%, 62 \cdot 1 \%$ and $42 \cdot 8 \%$, respectively). Multivariate logistic regression modelling showed that caregivers' family income and care will, and children's age and gender, were associated with caregivers' nutrition KAB after controlling the possible confounding variables (caregivers' age, gender, education and occupation).

Conclusions: Non-parent caregivers had relatively poor nutrition KAB. Extra efforts and targeted education programmes aimed to improve rural non-parent caregivers' nutrition $\mathrm{KAB}$ are wanted and need to be emphasized.
\end{abstract}

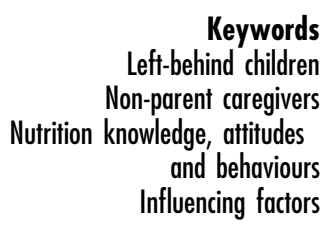

In recent years, the nutrition and health of left-behind children has become a social and public health problem in China ${ }^{(1-3)}$. When parents are unable to take care of their children, the responsibility falls to non-parent caregivers, either grandparents or other relatives ${ }^{(4,5)}$. Some studies have reported that Chinese children under 7 years old who lived with non-parent caregivers received less care and faced many nutrition-related problems, such as low intake of some nutrients and poor physical growth and development $^{(3,6,7)}$. Although there are various possible reasons for the nutrition-related problems of left-behind children, it is certain that caregivers' nutrition knowledge, attitudes and behaviours $(\mathrm{KAB})$ is an important factor.

Non-parent caregivers play a very important role in the daily care of rural left-behind children ${ }^{(3,8)}$; thus their nutrition $\mathrm{KAB}$ will be associated with the nutrition of rural left-behind children ${ }^{(9)}$. There is some literature on this topic $^{(10,11)}$. One study reported that because of non-parent caregivers' poor nutrition knowledge, rural left-behind children tended to be malnourished ${ }^{(10)}$. Another study revealed that non-parent caregivers' low knowledge regarding vitamin A was a critical factor for children's vitamin A deficiency ${ }^{(11)}$. However, these studies were mostly limited in scope and conducted with a small population, and there are few papers on non-parent caregivers' nutrition KAB in China. Clearly, such studies seem important because nonparent caregivers' nutrition $\mathrm{KAB}$ may enhance or impede the implementation and eventual success of a nutrition programme for left-behind children. Therefore, the purposes of the present study were to explore and compare nutrition $\mathrm{KAB}$ between non-parent and parent caregivers of children under 7 years old in Chinese rural areas, and to identify the factors influencing their nutrition KAB. The results of the study should provide information to develop tailored education programmes that meet the nutrition education needs of non-parent caregivers.

\section{Methods}

\section{Subjects and sampling}

The study population comprised non-parent and parent caregivers of children below 7 years of age living in Chinese rural areas. 
In our study, left-behind children were defined as those whose parents were farmers but were working out of the home town for at least 6 months up to the interviewing day. All of the left-behind children were under 7 years old and had been living in the same home town for the past 6 months. One of the child's principal caregivers in the family or extended family was selected as the study population.

This survey was a sub-project of the 'Investigation of left behind children's nutrition and health in Chinese rural areas'. Multistage stratified cluster and random sampling were adopted. First, seven representative provinces including Jiangxi, Sichuan, Hunan, Hubei, Guizhou, Henan and Anhui were selected randomly from the thirteen provinces that had the majority of the left-behind children (more than $80 \%$ ) according to data of the geographical distribution of left-behind children provided by the Population and Development Center of China(1). Second, three counties were selected randomly from each chosen province based on economic status, which was typical of good, fair and poor economic condition, respectively (twenty-one counties in total). Finally, in the same way, three towns were selected randomly from each chosen county (sixty-three towns in total). According to the definition of left-behind children, we ascertained the name list of left-behind children under 7 years old from the local government population register system and then randomly selected thirty left-behind children and their non-parent caregivers in each selected town after considering the distribution of children's age and gender.

Children in the parent caregivers' group were selected at the ratio of 1:1. Inclusion criteria included: the same residential area as the left-behind children (the same village or an adjoining village), the same gender, close age (age gap of less than 2-3 months) and other conditions such as similar birth weight and birth situation. According to the inclusion criteria, we first found these children in the local government population register system and then randomly selected them to match the sample of rural leftbehind child by age and sex. These children's parents were also enrolled as a comparative group.

\section{Measurements}

The questionnaire was based on items used in various published studies $^{(12,13)}$ and was developed by twelve experts through three waves of consultation (Delphi method). Our experts were from the departments of Nutrition Science, Child Health, Epidemiology and Statistics of different national universities, and they were all outstanding in their field. The questionnaire had been used in a pilot study ${ }^{(8)}$, and corresponding revision of two items was made according to the results of the pilot study. All topics in the questionnaire were strongly associated with the total score of $\mathrm{KAB}(r=0 \cdot 71-0 \cdot 90)$. We re-investigated 300 caregivers two weeks after the first investigation, and the Cronbach's $\alpha$ coefficient was computed to be $0 \cdot 80$.
The questionnaire was divided into four sections and comprised a series of questions pertaining to sociodemographic characteristics, basic nutrition knowledge, attitudes towards nutrition behaviours and behaviour characteristics with regard to children's nutrition.

The sociodemographic part of the instrument included questions on caregivers' age, gender, occupation and education level, and children's age and gender. For assessing basic nutrition knowledge, respondents were asked ten questions (see Table 2). If the answer was correct, a score of 1 was assigned. The maximum accumulated score was 10. For attitudes towards nutrition behaviour, respondents were asked to use a 2-point ordinal scale (rating scale from 0 to 2, 2= 'agree' and $0=$ 'disagree') in a limited number of questions exploring respondents' agreement/disagreement. This section had five questions (see Table 2) and the total score was 10. In the fourth set of questions, we assessed nutrition behaviours (see Table 2). This section also had five questions, and each question had five answers. The score of 4, 3, 2, 1 or 0 was assigned to the answer of 'strongly care', 'care', 'uncertain', 'do not care' and 'strongly do not care', respectively, and the maximum score was 20 . We classified the 'strongly care' and 'care' as the healthy behaviour, which meant 'yes' to the questions; the remaining three answers were classified as unhealthy behaviour, which meant 'no' to the questions.

The summation of knowledge, attitude and behaviour grades was equal to the total score of respondents. The rates of nutrition knowledge, positive attitude and optimal behaviour for each question were computed as the ratio of the number of people who gave a correct (positive) answer in the total answers.

\section{Protocol}

From October 2007 to September 2008, we carried out faceto-face interviews by using the questionnaire in the selected study areas. Before the formal investigation started, we organized a series of training programmes at nation, province and county level. The questionnaire was administered in the Chinese language. Caregivers voluntarily joined in this investigation. During the interview, interviewers read a list of questions, and caregivers listened to and answered each question honestly (10-15 min). After caregivers completed the questionnaire, their children received a free health examination as an incentive. If caregivers were reluctant to participate, we replaced them with others (same living area, gender, age, birth condition). Fortunately, most of our caregivers chose to accept interview, and the response rate was $96 \cdot 24 \%$.

Ethical committees from the Health Department of Jiangxi, Sichuan, Hunan, Hubei, Guizhou, Henan and Anhui provinces and all twenty-one chosen counties approved the research protocol; and informed, oral consent was obtained from the non-parent and parent caregivers. 


\section{Data analysis}

Chinese Version Epidata 3.0 (http://www.epidata.dk) was used to establish the database. The $\chi^{2}$ test was conducted to test for differences in sociodemographic characteristics and response rates of nutrition $\mathrm{KAB}$ between the two groups. Multivariable logistic regression modelling was used to identify the factors influencing $\mathrm{KAB}$ among caregivers (backward method: $\operatorname{LR} \alpha_{\text {in }}=0 \cdot 05, \alpha_{\text {out }}=0 \cdot 10$ ). The significance level for variables entering the models was set at $0 \cdot 05$ and for removing at $0 \cdot 10$. Associations between the independent and dependent variables were expressed as odds ratios, adjusted odds ratios and 95\% confidence intervals. The level of significance was set at 0.05 and all $P$ values were interpreted in a two-tailed manner.

\section{Results}

\section{Basic situation}

A total of 3800 questionnaires were returned. Among these questionnaires only 3361 were valid (88.45\%), and the remaining 439 were excluded from the analysis because of missing data. Among the 3361 respondents, $1691(50 \cdot 3 \%)$ were non-parent caregivers and 1670 (49.7\%) were parent caregivers. There were significant differences in gender, age, occupation and education between non-parent and parent caregivers. Compared with parent caregivers, there were more females, farmers, seniors and low-educated persons in the group of nonparent caregivers. As for the children, the mean age and the age and gender distributions of the left-behind children were similar to those of the comparative group; none of the between-group comparisons were statistically significant (Table 1).

\section{Comparison of pass rates on child nutrition knowledge, attitudes and bebaviours between non- parent and parent caregivers}

As illustrated in Table 2, there were significant differences in the answers to the questions of nutrition KAB between non-parent and parent caregivers. For example, the rates of correct answers to the ten nutrition knowledge questions were significantly lower in non-parent caregivers than in parent caregivers. Similarly, compared with parent caregivers, the rates of positive attitudes and the rates of healthy nutrition behaviours were also significantly lower in non-parent caregivers, except for three questions (Table 2).

\section{Multivariable logistic regression analysis on the factors influencing caregivers' nutrition knowledge, attitudes and bebaviours}

Six variables that showed a significant difference for caregivers' $\mathrm{KAB}$ in the univariate analyses, including caregiver's family income and care will, child's age and gender, type of guardianship and child's living fee paid by parents, were selected to be independent variables. Whether the total score passed or not was taken as the dependent variable $(0=$ passed, $1=$ failed $)$ and then

Table 1 Comparison of caregivers' and children's demographic characteristics, rural China (Jiangxi, Sichuan, Hunan, Hubei, Guizhou, Henan and Anhui provinces), 2007-2008

\begin{tabular}{|c|c|c|c|c|c|c|}
\hline \multirow[b]{2}{*}{ Characteristic } & \multicolumn{2}{|c|}{ Non-parent caregivers } & \multicolumn{2}{|c|}{ Parent caregivers } & \multirow[b]{2}{*}{$\chi^{2}$} & \multirow[b]{2}{*}{$P$} \\
\hline & $n$ & $\%$ & $n$ & $\%$ & & \\
\hline \multicolumn{7}{|l|}{ Caregiver's gender } \\
\hline Male & 534 & $31 \cdot 6$ & 642 & $38 \cdot 4$ & $17 \cdot 404$ & 0.000 \\
\hline Female & 1157 & $68 \cdot 4$ & 1028 & $61 \cdot 6$ & & \\
\hline \multicolumn{7}{|l|}{ Age group (years) } \\
\hline$\leq 35$ & 507 & $30 \cdot 0$ & 999 & $59 \cdot 8$ & $713 \cdot 671$ & 0.000 \\
\hline $36-50$ & 294 & $17 \cdot 4$ & 505 & $30 \cdot 3$ & & \\
\hline$\geq 50$ & 889 & $52 \cdot 6$ & 165 & $9 \cdot 9$ & & \\
\hline \multicolumn{7}{|l|}{ Occupation } \\
\hline Farmer & 1594 & $94 \cdot 3$ & 1427 & $85 \cdot 4$ & $76 \cdot 466$ & 0.000 \\
\hline Businessman & 39 & $2 \cdot 3$ & 129 & $7 \cdot 7$ & & \\
\hline White-collar worker & 39 & $2 \cdot 3$ & 85 & $5 \cdot 1$ & & \\
\hline Other & 19 & $1 \cdot 1$ & 29 & $1 \cdot 7$ & & \\
\hline \multicolumn{7}{|l|}{ Education level } \\
\hline Illiterate or semi-literate & 533 & 31.5 & 166 & $9 \cdot 9$ & $294 \cdot 476$ & 0.000 \\
\hline Elementary school & 568 & $33 \cdot 6$ & 518 & $31 \cdot 0$ & & \\
\hline Junior middle school & 508 & $30 \cdot 0$ & 843 & $50 \cdot 5$ & & \\
\hline High school or above & 82 & $4 \cdot 8$ & 143 & $8 \cdot 6$ & & \\
\hline Child's age group (years) & & & & & $0 \cdot 263$ & 0.967 \\
\hline$<3$ & 306 & $18 \cdot 1$ & 294 & $17 \cdot 6$ & & \\
\hline 3- & 583 & $34 \cdot 5$ & 586 & $35 \cdot 1$ & & \\
\hline $5-$ & 603 & $35 \cdot 7$ & 598 & $35 \cdot 8$ & & \\
\hline 7 & 199 & $11 \cdot 8$ & 192 & $11 \cdot 5$ & & \\
\hline Child's gender & & & & & 0.094 & 0.782 \\
\hline Male & 873 & $51 \cdot 6$ & 871 & $52 \cdot 2$ & & \\
\hline Female & 818 & $48 \cdot 4$ & 799 & $47 \cdot 8$ & & \\
\hline
\end{tabular}


Table 2 Comparison of parent and non-parent caregivers' pass rates for child nutrition knowledge, attitudes and behaviours (KAB), rural China (Jiangxi, Sichuan, Hunan, Hubei, Guizhou, Henan and Anhui provinces), 2007-2008

\begin{tabular}{|c|c|c|c|c|c|c|c|}
\hline \multirow[b]{2}{*}{ KAB item } & \multirow{2}{*}{$\begin{array}{l}\text { Correct (positive) } \\
\text { answer }\end{array}$} & \multicolumn{2}{|c|}{$\begin{array}{l}\text { Non-parent } \\
\text { caregivers }\end{array}$} & \multicolumn{2}{|c|}{$\begin{array}{l}\text { Parent } \\
\text { caregivers }\end{array}$} & \multirow[b]{2}{*}{$\chi^{2}$} & \multirow[b]{2}{*}{$P$} \\
\hline & & $n$ & $\%$ & $n$ & $\%$ & & \\
\hline \multicolumn{8}{|l|}{ Knowledge } \\
\hline $\begin{array}{l}\text { 1. Which nutrient ingredient can be supplemented if children } \\
\text { often eat fresh fruits and vegetables? }\end{array}$ & $\begin{array}{l}\text { vitamins and dietary } \\
\text { fibre }\end{array}$ & 774 & $45 \cdot 8$ & 1061 & $63 \cdot 5$ & $106 \cdot 93$ & $0 \cdot 000$ \\
\hline 2. Does it affect health if children eat fried food too much? & yes & 991 & $58 \cdot 6$ & 1169 & $70 \cdot 0$ & $47 \cdot 22$ & $0 \cdot 000$ \\
\hline $\begin{array}{l}\text { 3. Is it necessary for children to be afforded a variety of } \\
\text { tonics frequently? }\end{array}$ & no & 761 & $45 \cdot 0$ & 863 & $51 \cdot 7$ & $15 \cdot 12$ & 0.000 \\
\hline $\begin{array}{l}\text { 4. Is it able to fully meet the needs of growth and } \\
\text { development as long as children eat more meat, } \\
\text { fish and eggs? }\end{array}$ & no & 836 & $49 \cdot 4$ & 1050 & $62 \cdot 9$ & $61 \cdot 59$ & $0 \cdot 000$ \\
\hline $\begin{array}{l}\text { 5. Which has more nutrition value, rough flour or } \\
\text { refined flour? }\end{array}$ & rough flour & 764 & $45 \cdot 2$ & 866 & $51 \cdot 9$ & $14 \cdot 99$ & $0 \cdot 000$ \\
\hline $\begin{array}{l}\text { 6. What is the best way to prevent children calcium } \\
\text { deficiency? }\end{array}$ & $\begin{array}{l}\text { basking and } \\
\text { supplement calcium }\end{array}$ & 519 & $30 \cdot 7$ & 734 & $44 \cdot 0$ & $63 \cdot 38$ & $0 \cdot 000$ \\
\hline $\begin{array}{l}\text { 7. Is it reasonable for children have a poor breakfast but } \\
\text { a rich lunch and dinner? }\end{array}$ & no & 880 & $52 \cdot 0$ & 1066 & $63 \cdot 9$ & $48 \cdot 23$ & $0 \cdot 000$ \\
\hline 8. Is the nutrition value of milk substitute equal to milk? & no & 990 & $58 \cdot 5$ & 1169 & $70 \cdot 0$ & $47 \cdot 70$ & $0 \cdot 000$ \\
\hline $\begin{array}{l}\text { 9. Is it better to wash the rice as many as possible while } \\
\text { cooking? }\end{array}$ & no & 1031 & $61 \cdot 0$ & 1258 & $75 \cdot 3$ & $79 \cdot 36$ & $0 \cdot 000$ \\
\hline $\begin{array}{l}\text { 10. Should children often eat fast food, such as } \\
\text { McDonald's and KFC? }\end{array}$ & no & 1278 & $75 \cdot 6$ & 1416 & $84 \cdot 8$ & $44 \cdot 44$ & $0 \cdot 000$ \\
\hline Subtotal & & 8824 & $52 \cdot 2$ & 10652 & $63 \cdot 8$ & $464 \cdot 14$ & $0 \cdot 000$ \\
\hline \multicolumn{8}{|l|}{ Attitudes } \\
\hline $\begin{array}{l}\text { 1. Will you give priority to the nutrition value when you } \\
\text { choose food for children? }\end{array}$ & agree & 1099 & $65 \cdot 0$ & 1191 & $71 \cdot 3$ & $15 \cdot 30$ & $0 \cdot 000$ \\
\hline $\begin{array}{l}\text { 2. Do you agree with your child eating the low nutrition } \\
\text { value food too much? }\end{array}$ & disagree & 1129 & $66 \cdot 8$ & 1223 & $73 \cdot 3$ & $16 \cdot 96$ & $0 \cdot 000$ \\
\hline $\begin{array}{l}\text { 3. Do you remind your child of food diversification, not } \\
\text { being choosy in food and monophobia while eating? }\end{array}$ & agree & 1284 & $75 \cdot 9$ & 1392 & $83 \cdot 4$ & $28 \cdot 52$ & $0 \cdot 000$ \\
\hline 4. Do you think children should drink milk every day? & agree & 906 & $53 \cdot 6$ & 971 & $58 \cdot 2$ & $7 \cdot 21$ & 0.004 \\
\hline $\begin{array}{l}\text { 5. Is it necessary to prepare separate food for children } \\
\text { under } 7 \text { years old? }\end{array}$ & agree & 426 & $25 \cdot 2$ & 409 & $24 \cdot 5$ & $1 \cdot 546$ & $0 \cdot 462$ \\
\hline Subtotal & & 4810 & 56. 9 & 5186 & $62 \cdot 1$ & $47 \cdot 47$ & $0 \cdot 000$ \\
\hline \multicolumn{8}{|l|}{ Behaviours } \\
\hline 1. Do you prepare breakfast for your child every day? & yes (5-7/week) & 1154 & $68 \cdot 2$ & 1280 & $76 \cdot 6$ & $2 \cdot 71$ & $0 \cdot 054$ \\
\hline 2. Do you prepare milk or soya milk for your child every day? & yes (5-7/week) & 504 & $29 \cdot 8$ & 580 & $34 \cdot 7$ & $9 \cdot 33$ & 0.001 \\
\hline 3. Do you prepare calcium for your child every day? & yes (5-7/week) & 151 & $8 \cdot 9$ & 161 & $9 \cdot 6$ & 0.51 & $0 \cdot 258$ \\
\hline $\begin{array}{l}\text { 4. Do you remind your child of food diversification, not being } \\
\text { choosy in food and monophobia while eating? }\end{array}$ & yes (5-7/week) & 808 & $47 \cdot 8$ & 891 & $53 \cdot 4$ & $10 \cdot 43$ & 0.001 \\
\hline $\begin{array}{l}\text { 5. Do you try to change your child's diet in order to enhance } \\
\text { nutrition? }\end{array}$ & yes (5-7/week) & 526 & $31 \cdot 1$ & 663 & $39 \cdot 7$ & $27 \cdot 15$ & 0.000 \\
\hline Subtotal & & 3143 & $37 \cdot 7$ & 3575 & $42 \cdot 8$ & $55 \cdot 71$ & 0.000 \\
\hline
\end{tabular}

For knowledge, $n$ represents the number of people with the correct response; for attitudes, $n$ represents the number of people in a positive attitude; for behaviours, $n$ represents the number of people with the correct behaviour.

multivariable logistic regression analysis was conducted. After controlling for possible confounding variables, caregivers' family income and care will, and children's age and gender, were associated with caregivers' KAB (Table 3).

\section{Discussion}

\section{Status of nutrition knowledge, attitudes and bebaviours among non-parent caregivers}

In the present study we found that the awareness rate of nutrition knowledge, the rate of positive attitudes and the rate of correct behaviours in non-parent caregivers were significantly lower than in parent caregivers $(52 \cdot 2 \% v$.
$63 \cdot 8 \%, 56 \cdot 9 \% v \cdot 62 \cdot 1 \%$ and $37 \cdot 7 \%$ v. $42 \cdot 8 \%$, respectively). These rates were also lower than those in parent caregivers in Zhuhai, Guangdong Province, China, in whom the rates of nutrition knowledge, positive attitudes and correct behaviours were $72 \cdot 21 \%, 82 \cdot 49 \%$ and $67 \cdot 4 \%$, respectively ${ }^{(14)}$. Our findings indicated that there was a significant lack of nutrition KAB among the non-parent caregivers.

According to the theory of knowledge-attitude-practice or knowledge-attitude-behaviour-practice, we know that knowledge is the foundation of a correct behaviour and a positive attitude is the driving force of a correct behaviour; if a person is to perform a particular behaviour, he or she must know what the behaviour is (knowledge of the behaviour) 
Table 3 Multivariable logistic regression analysis on the factors influencing caregivers' nutrition knowledge, attitudes and behaviours, rural China (Jiangxi, Sichuan, Hunan, Hubei, Guizhou, Henan and Anhui provinces), 2007-2008

\begin{tabular}{|c|c|c|c|c|c|c|}
\hline & $P$ & Crude OR & $95 \% \mathrm{Cl}$ & $P$ & Adjusted OR & $95 \% \mathrm{Cl}$ \\
\hline Guardianship type & 0.000 & & & 0.464 & & \\
\hline Parents' guardianship & & 1.000 & reference & & 1.000 & reference \\
\hline Inter-generational care & 0.000 & 1.596 & $1 \cdot 285,1 \cdot 982$ & 0.653 & 0.943 & $0.728,1.220$ \\
\hline Other & 0.564 & 0.788 & $0.350,1 \cdot 773$ & 0.223 & 0.591 & $0.254,1.376$ \\
\hline Family income (RMB Yuan/year) & 0.000 & & & 0.000 & & \\
\hline$\leq 2000$ & & $1 \cdot 000$ & reference & & $1 \cdot 000$ & reference \\
\hline $2001-4000$ & 0.001 & 0.754 & $0.635,0.894$ & 0.043 & 0.832 & $0.697,0.994$ \\
\hline$\geq 4000$ & 0.000 & 0.489 & $0.410,0.584$ & 0.000 & 0.589 & $0.489,0.710$ \\
\hline Care will & 0.007 & & & 0.019 & & \\
\hline Very pleased & & $1 \cdot 000$ & reference & & 1.000 & reference \\
\hline Pleased & 0.005 & $1 \cdot 350$ & $1.095,1.664$ & 0.007 & $1 \cdot 349$ & $1 \cdot 086,1 \cdot 677$ \\
\hline Unwilling & 0.023 & $1 \cdot 743$ & $1 \cdot 079,2 \cdot 816$ & 0.095 & 1.522 & $0.929,2.493$ \\
\hline Child's age (years) & 0.000 & & & 0.000 & & \\
\hline$<3$ & & $1 \cdot 000$ & reference & & $1 \cdot 000$ & reference \\
\hline 3- & 0.508 & $1 \cdot 071$ & $0 \cdot 874,1 \cdot 312$ & 0.497 & 1.076 & $0.871,1.328$ \\
\hline $5-$ & 0.037 & $1 \cdot 241$ & $1 \cdot 013,1 \cdot 520$ & 0.272 & $1 \cdot 125$ & $0.912,1.390$ \\
\hline 7 & 0.000 & 1.981 & $1 \cdot 507,2 \cdot 604$ & 0.000 & $1 \cdot 848$ & $1 \cdot 390,2 \cdot 475$ \\
\hline Child's gender & 0.008 & & & 0.003 & & \\
\hline Male & & $1 \cdot 000$ & reference & & $1 \cdot 000$ & reference \\
\hline Female & 0.008 & $1 \cdot 210$ & $1 \cdot 050,1 \cdot 393$ & 0.003 & $1 \cdot 250$ & $1 \cdot 079,1 \cdot 448$ \\
\hline
\end{tabular}

Logistic regression model adjusted for caregivers' age, gender, education and occupation.

and how to perform it (skill) ${ }^{(15)}$. Thus, nutrition knowledge and attitudes appear to be important factors that drive correct nutrition behaviours. In this sense, targeted nutrition education programmes aimed to improve rural non-parent caregivers' nutrition $\mathrm{KAB}$ are wanted and need to be emphasized.

Factors influencing nutrition knowledge, attitudes and bebaviours among non-parent caregivers

Non-parent caregivers, especially grandparents, are dependent on the economy as there is no proper financial aid from social welfare; therefore, it affects the wellness of children if these caregivers are financially unstable ${ }^{(6)}$. Ramadasmurthy et al. also found that household income was the most crucial factor limiting the dietary $\mathrm{KAB}^{(16)}$. In the current study, the family income of non-parent caregivers was significantly lower than that of the parent caregivers, and multivariate logistic regression analysis demonstrated that caregivers' family income had a positive association with nutrition KAB. This finding could be attributable to the fact that perhaps caregivers with a highincome family had more ability in children's diet/nutrition and they cared more about their nutrition knowledge in order to improve their children's nutrition status.

In multivariate logistic regression analysis, the results displayed that the weaker the care will, the lower the caregivers' nutrition KAB. In our study, about $20 \%$ of non-parent caregivers had weaker care will; of course, the weaker care would affect caregivers' learning about nutrition knowledge and their attitudes and behaviours when caring for children. These findings are in keeping with other literature, which showed that having strong care will was a driving force for a person to improve his/ her nutrition $\mathrm{KAB}^{(14)}$. This factor has seldom been con- sidered when nutrition $\mathrm{KAB}$ is involved; however, it should never be overlooked.

Children's age could be another factor associated with caregivers' nutrition $\mathrm{KAB}$, especially in terms of nutrition attitudes and behaviours. Our study demonstrated that caregivers' nutrition $\mathrm{KAB}$ was better in the group of children below 3 years old and poor in the group of children aged 7 years. These results concur with several studies that have assessed the relationship of child age and caregiver's nutrition $\mathrm{KAB}^{(17,18)}$.

A significant association was also found between the child's gender and the caregiver's nutrition KAB. Specifically, the nutrition KAB was better in caregivers who looked after boys than in those who cared for girls. The result may reveal some traditional values in the grandparent caregivers, particularly in economically backward rural areas, that 'Boys are superior to girls' and 'Boys will be good labourers and can do more hard work'. This is embodied by caregivers in that they care for boys more carefully and usually they are likely to get more health nutrition $\mathrm{KAB}$ in order to promote their boys' health. In previous research, when discussing the factors influencing caregivers' nutrition $\mathrm{KAB}$, many focused on characteristics related to the caregivers themselves, not on factors related to the children. However, these factors really impact caregivers' nutrition $\mathrm{KAB}$, which should be explored in further study.

The current study has some limitations. The measurement of nutrition KAB was relatively superficial, as the caregivers' sociodemographic characteristics, especially non-parent caregivers, precluded the use of a more detailed measure. In addition, nutrition $\mathrm{KAB}$ was ascertained based on criteria established by experts in three waves of consultation. A standard method to evaluate 
caregivers' nutrition $\mathrm{KAB}$ is urgently needed for future research. Another limitation is a possible bias from caregivers' answers to the questions. We adopted face-to-face interviews; however caregivers, especially some nonparent caregivers, could have misunderstood some the questions because of their old age and low education, and kept something back when reporting nutrition KAB. Thus answer bias was unavoidable in our interview-based investigation. Finally, the study population involved leftbehind children below 7 years of age only, and we are not sure whether the results can be generalized to leftbehind children at large.

Despite these limitations, the present study is the first to report the nutrition $\mathrm{KAB}$ among non-parent caregivers of left-behind children under 7 years old. In addition, we have identified the factors influencing nutrition KAB by multivariable logistic regression modelling, which bears importance in health education and health promotion programmes for left-behind children's nutrition in Chinese rural areas.

\section{Acknowledgements}

This work was funded by the Department of Children in the Bureau of Women's Health Care and the Department of Community Health Services of the Ministry of Health (CWSB 20070012). There are no conflicts of interest between the conducting organization and the support organization. Every author has no conflicts of interest. The paper was accomplished mainly by C.T., J.L. and R.Z. J.L. and R.Z. were also the main members of the project, and gave many constructive suggestions on the manuscript in writing and revision. C.F., L.Z., J.M. and D.D. took part in the investigation and data analysis. We are extremely grateful to the administrative units (Jiangxi, Sichuan, Hunan, Hubei, Guizhou, Henan and Anhui) involved in the project and the investigation staff who worked hard and made a great contribution to the project.

\section{References}

1. Duan CR \& Yang K (2008) The study of rural left behind children in our country. J Popul Res 32, 15-25.
2. Peng XC, Luo JY, Yao KB et al. (2008) The status on care and nutrition of 774 children staying in rural areas while parents were in towns. Chin J Epidemiol 29, 860-864.

3. Duan DH, Zhu MY, Luo JY et al. (2009) Investigation on dietary nutrients among rural stranded children aged 2-7 years old in China. Chin J Epidemiol 30, 326-329.

4. Smith AB, Dannison LL \& Tammy V-H (1998) When 'grandma' is 'mom': what today's teachers need to know. Child Educ 75, 12-16.

5. Bégin F, Frongillo EA Jr \& Delisle H (1999) Caregiver behaviors and resources influence child height-for-age in rural Chad. J Nutr 129, 680-686.

6. Luo JY, Peng XC, Zong R et al. (2008) The status of care and nutrition of 774 left-behind children in rural areas in China. Public Health Rep 123, 382-389.

7. Mou JS, Luo JY, Li YP et al. (2009) Study on the nutritional status and determinants among rural children without parents around/in China. Chin J Epidemiol 30, 425-428.

8. Tan C, Luo JY, Wang Z et al. (2009) Knowledge-attitudepractice and related determinants on nutrition among caregivers of rural stranded children under 7 years old in China. Chin J Epidemiol 30, 588-592.

9. Manios Y, Moschandreas J, Hatzis C et al. (1999) Evaluation of a health and nutrition education program in primary school children of Crete over a three-year period. Prev Med 28, 149-159.

10. Zhong JC \& Wang J (2006) Health problems of children staying behind in the countryside. Chin Prim Health Care 20, 69-70.

11. Mills JP, Mills TA \& Reicks M (2007) Caregiver knowledge, attitudes and practices regarding vitamin A intake by Dominican children. Matern Child Nutr 3, 58-68.

12. Wei M \& Yuan LJ (2007) Survey on 1-6 year old children's parents' nutrition KAB. Shanghai J Prev Med 19, 288-289.

13. Ding Y (2005) Survey on parents' nutrition KAB in Xinxiang. J Med Forum 26, 4-6.

14. Chen MX, He W, Fu ZY et al. (2003) Multiple factors analysis on malnutrition of children and under five in different patterns in China in 2000. J Hyg Res 3, 249-253.

15. Sharma SV, Gernand AD \& Day RS (2008) Nutrition knowledge predicts eating behavior of all food groups except fruits and vegetables among adults in the Paso del Norte region: Qué Sabrosa Vida. J Nutr Educ Behav 40, 361-368.

16. Ramadasmurthy $\mathrm{V}$, Mohanram M, Visweswara Rao $\mathrm{K}$ et al. (1992) Role of communication media in nutrition knowledge and awareness. An Indian urban study. Int J Food Sci Nutr 43, 121-128.

17. Messina CR, Weidner G \& Connor SL (2002) Mothers' attitudes toward nutrition are related to daughters' but not to sons' plasma cholesterol levels. J Am Diet Assoc 102, 678-682.

18. Pelto GH, Santos I, Goncalves H et al. (2004) Nutrition counseling training changes physician behavior and improves caregiver knowledge acquisition. J Nutr 134, $357-362$. 